\title{
VESTÍGIOS - POR UMA ETNOGRAFIA DA PRESENÇA
}

Gustavo Racy ${ }^{1}$

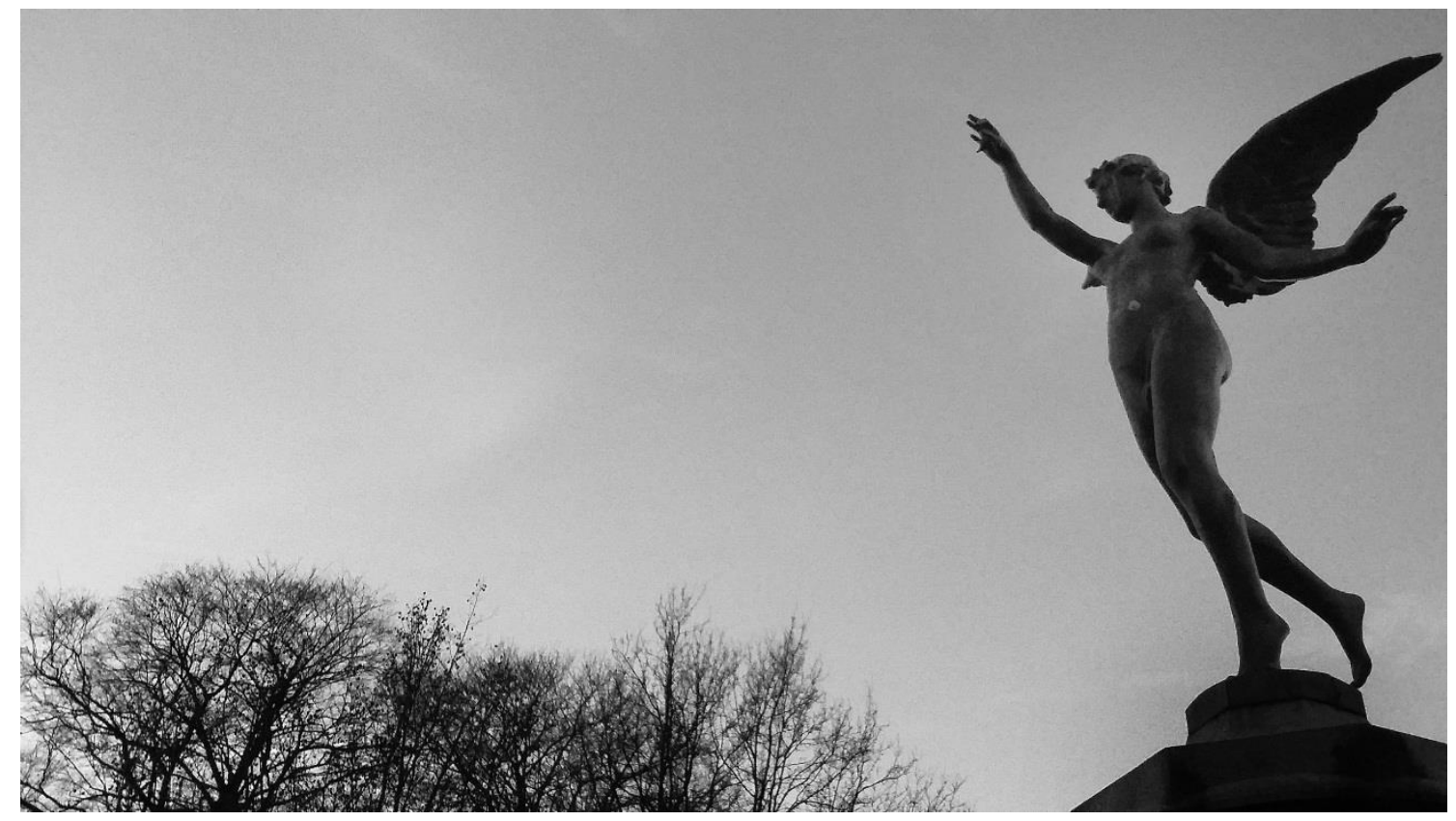

1. Stadspark, Antuérpia. 2016.

2. Vista do trem entre Bruxelas e Antuérpia. 2015.

\footnotetext{
${ }^{1}$ Universidade da Antuérpia, Bélgica.
}

Iluminuras, Porto Alegre, v. 18, n. 45, p. 425-431, ago/dez, 2017. 


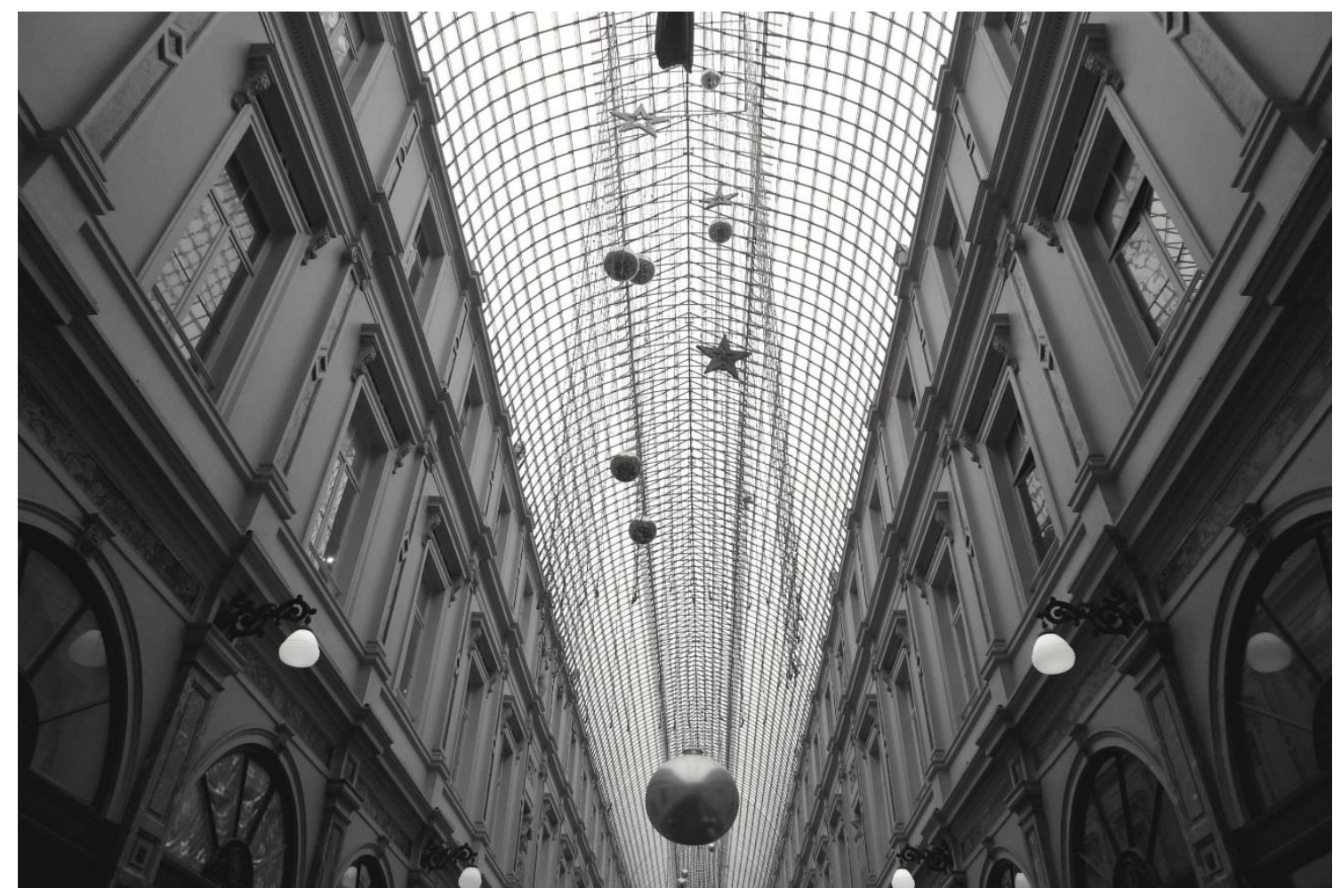

3. Galeria Real Saint-Hubert, Bruxelas. 2016.

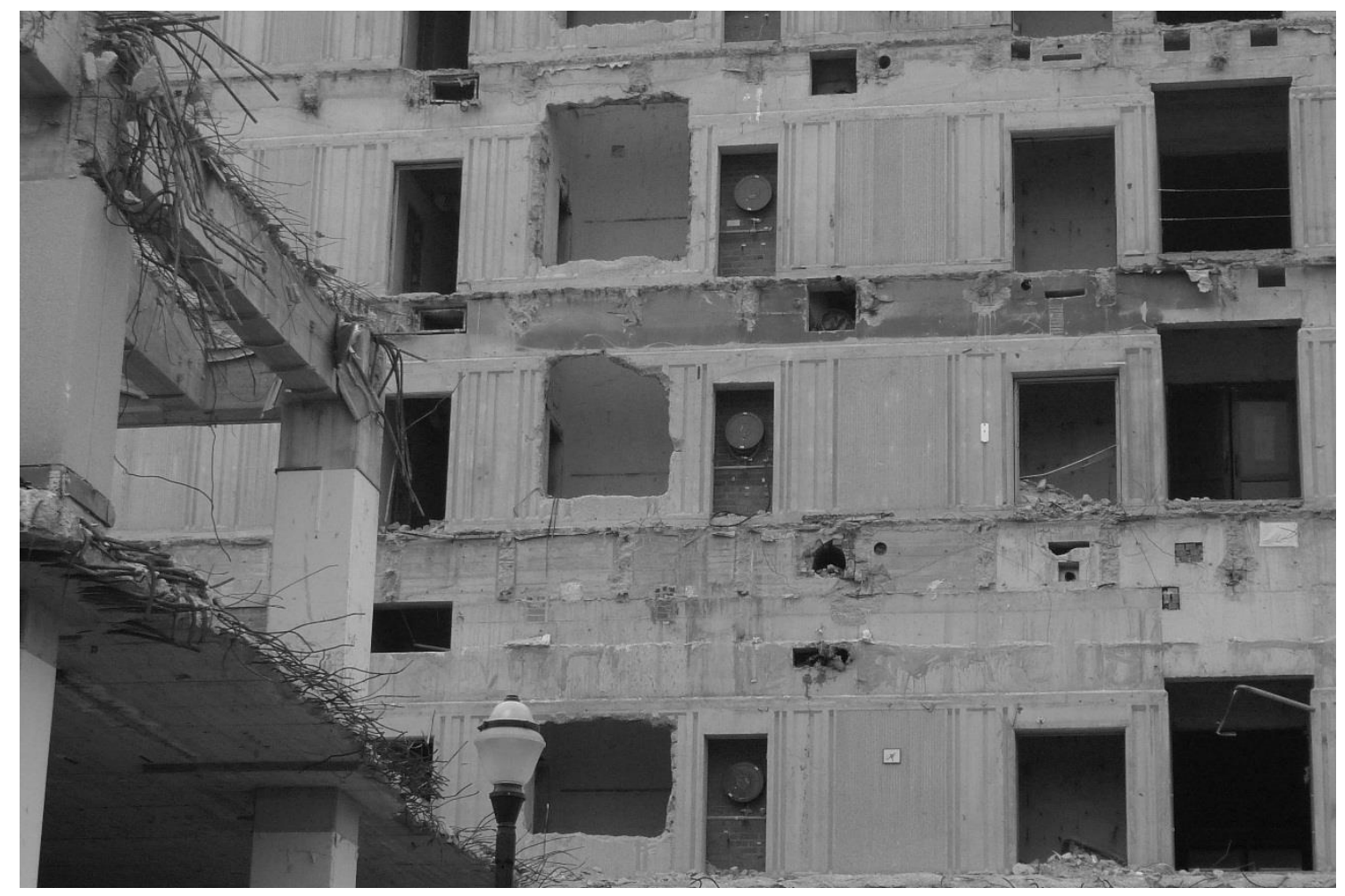

4. Quartos e corredores, Bruxelas. 2016. 


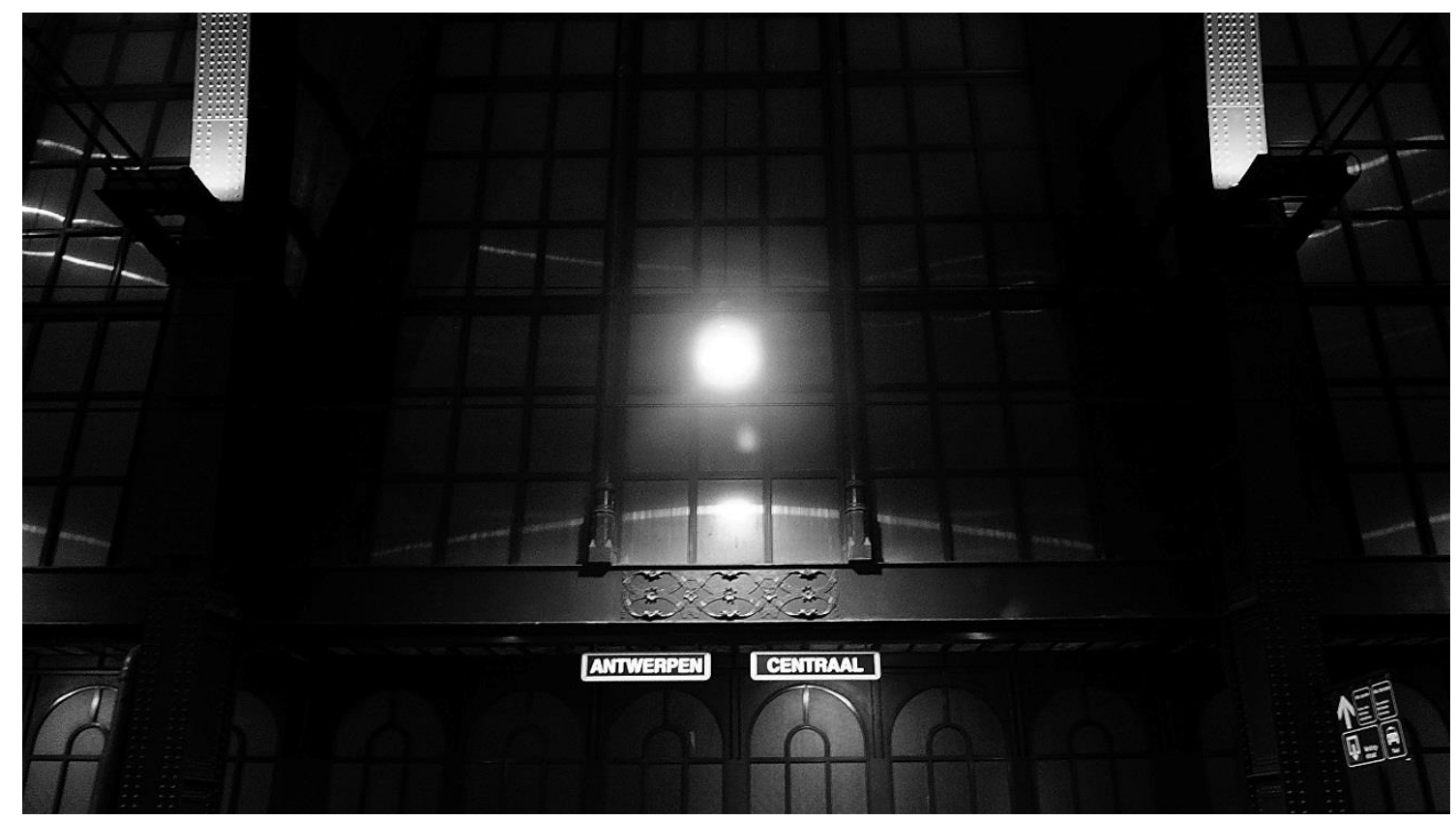

5. Estação Central, Antuérpia. 2016.

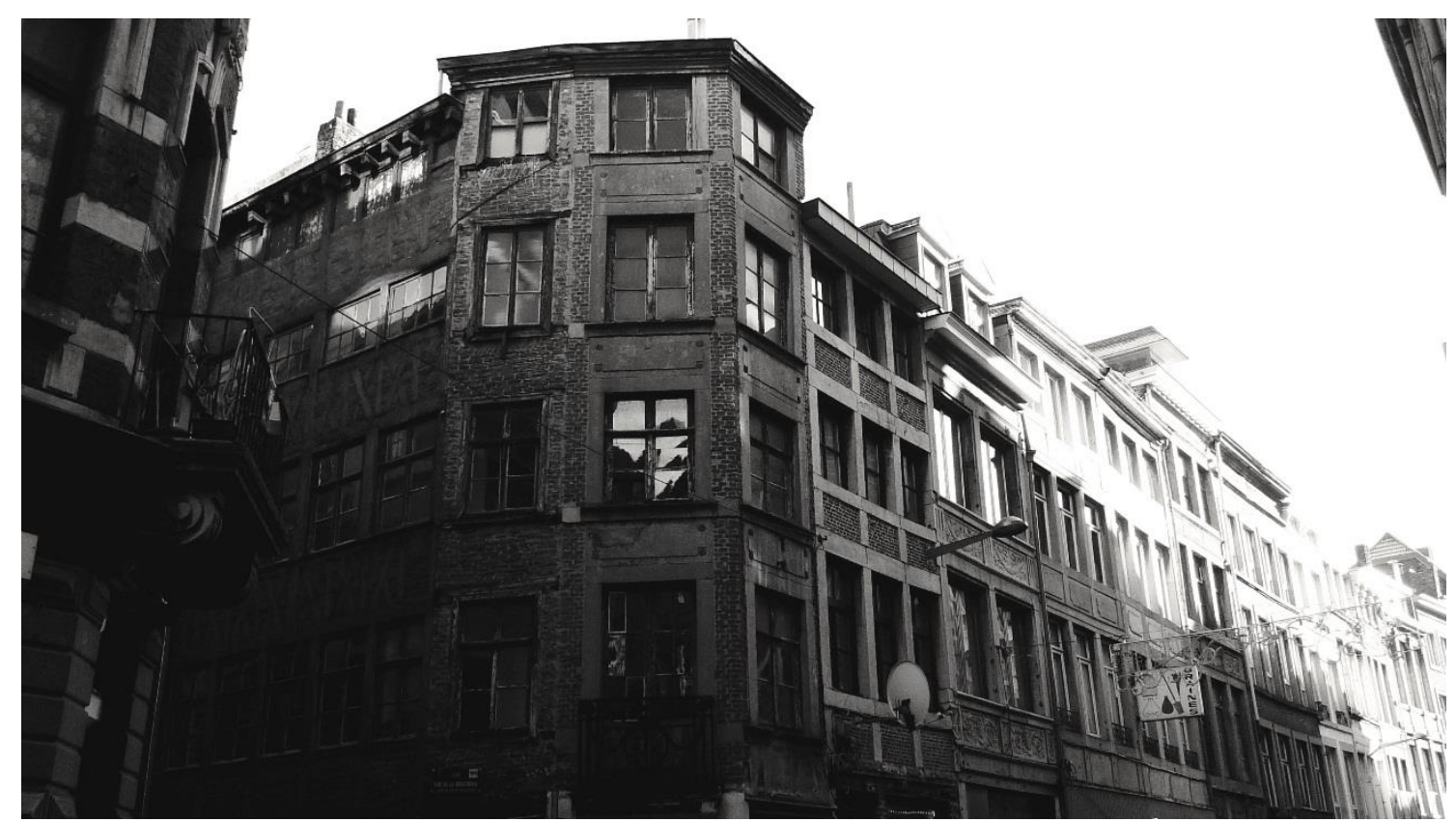

6. Habitar ausente, Liège. 2016. 


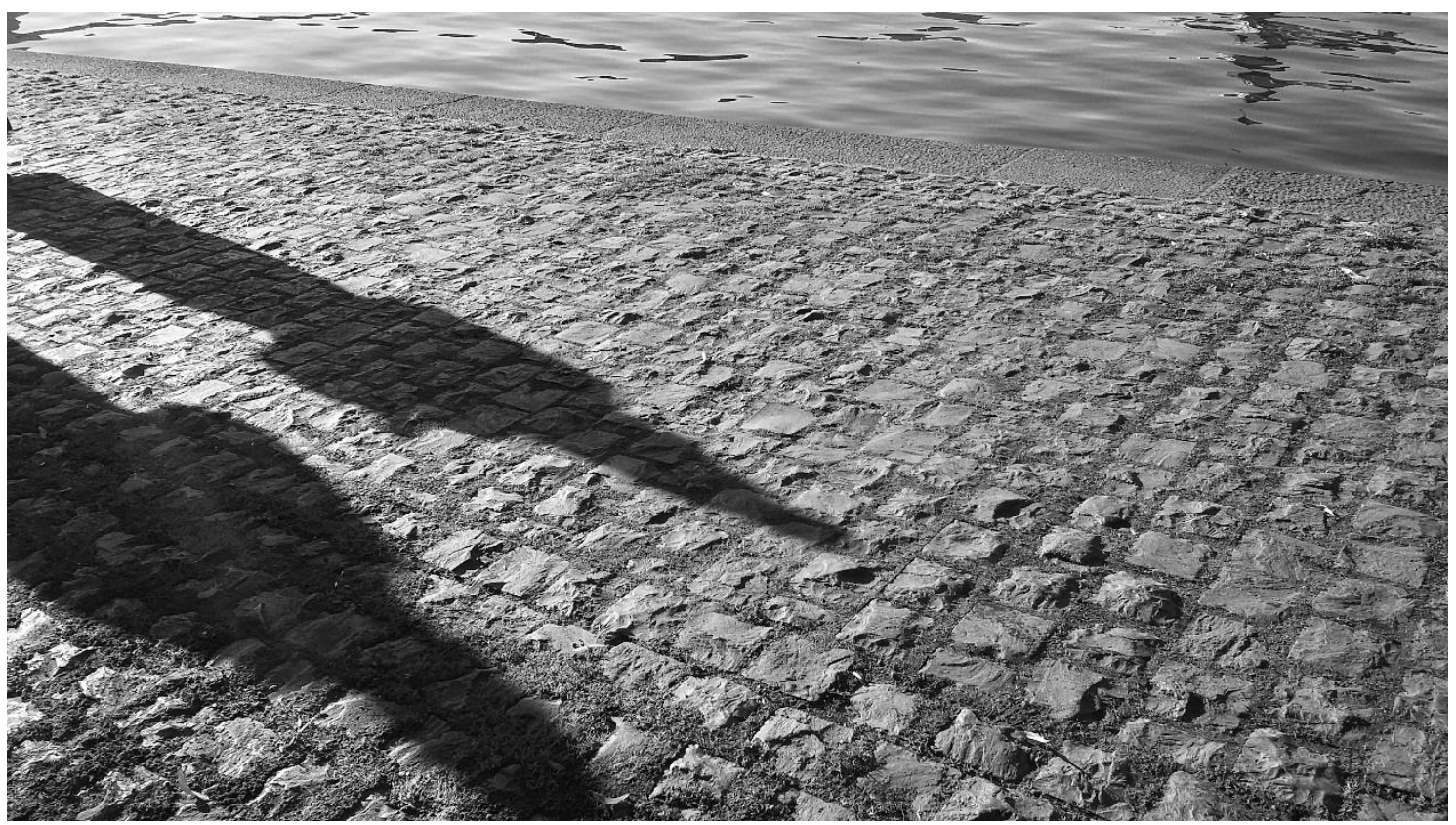

7. Promenade, Liège. 2016.

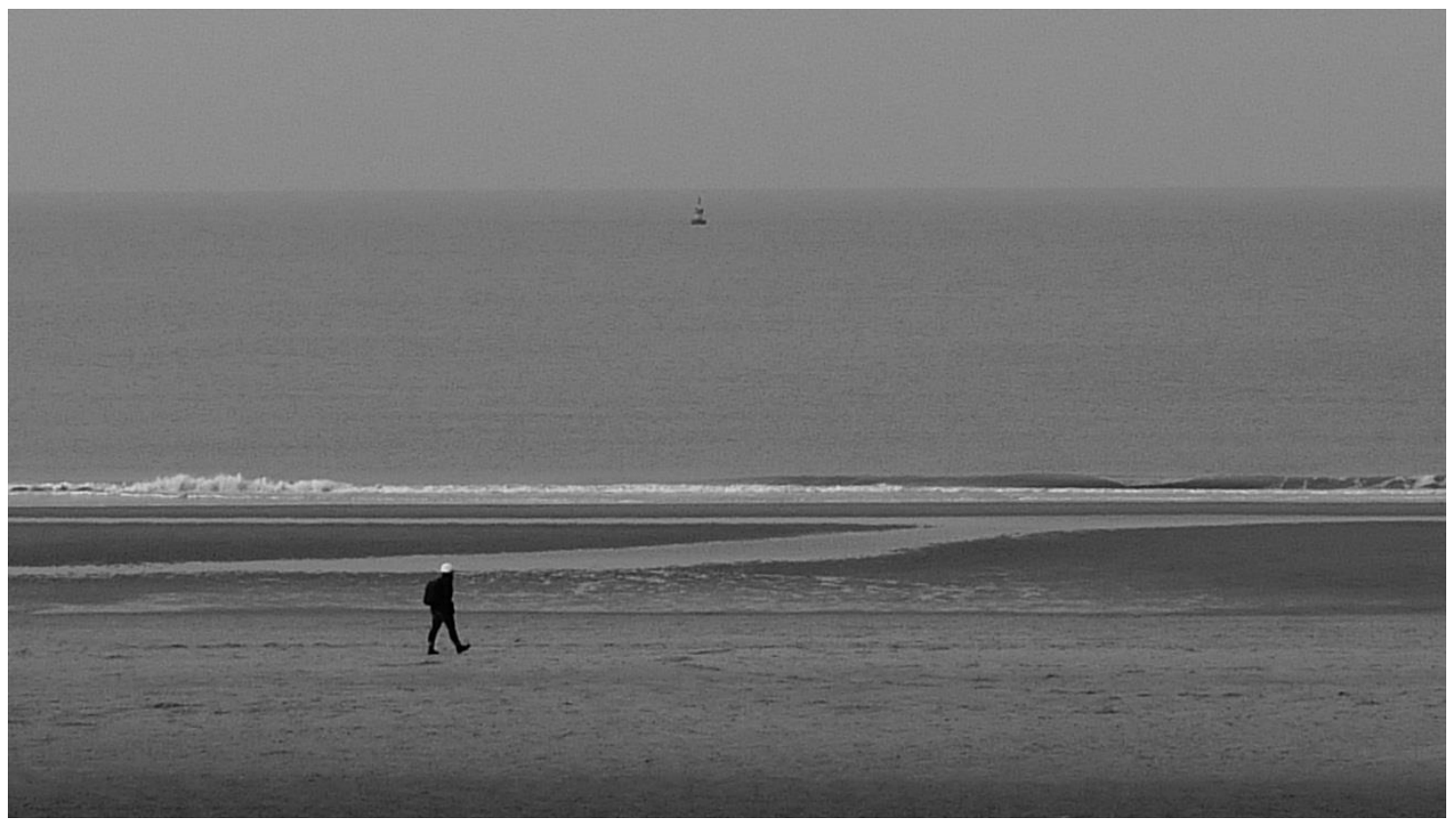

8. Caminhante, Oostende. 2015.

Registradas ao longo de dois anos entre quatro cidades belgas, as fotos que compõem o presente ensaio ensejam uma reflexão acerca de nossa relação de presença no meio urbano. Em termos geográficos e demográficos, as cidades belgas, mesmo Bruxelas, dificilmente espantarão nativos de uma metrópole ou megalópole globais. Seus atrativos, no entanto, jazem precisamente nessa incomparável pequenez relativa às grandes metrópoles, que reserva momentos em que um caminhante pode se encontrar 
sozinho por ruas, avenidas e vielas. Essa estranha experiência de ausência em meio ao complexo urbano, não obstante, é composta por uma série de estímulos de ordem sensorial que leva o sujeito a empreender nova relação com o meio urbano. Ainda que cercado por ausência, o caminhante é cercado de vestígios de presença humana que podem leva-lo a reconsiderar e reconfigurar noções de presença na cotidianidade. O que significa fazer-se presente? O que é a presença em quanto modo de existência (solidão, habitar, co-existir, etc.) e experiência cotidiana? Se é inevitável, de que se trata e como se dá a presença?

Vistas de uma janela de trem, estruturas de ferro, monumentos religiosos, prédios vazios e mesmo uma boia indicam, no ensaio, precisamente os vestígios que nos cercam no dia-a-dia e que, talvez inconscientemente, nos remetem à inevitável experiência da presença. Como é possível estar sozinho, se por todo lado estamos cercados de presença humana? Sobre o aposento burguês da década de 1880, Walter Benjamin (2000: 266) declarara "[...] a impressão mais forte, em meio de todo 'aconchego' que talvez irradie, é: - Aqui não tens nada a procurar. - E isto porque não há canto no qual o morador já não tenha deixado seu vestígio". Ora, mas o que dizer dos vestígios deixados pelos habitantes da cidade no espaço exterior? É precisamente acerca destes vestígios que as cidades belgas, acima e abaixo, adiante e atrás, oferecem ao etnógrafo possibilidades distintas de articulação sobre relações de presença humana no espaço social.

Na tentativa de investigar a questão através da fotografia, retoma-se, também, uma relação particular à Bélgica no tocante às artes visuais e à literatura. Foi aí que um dos primeiros e mais importantes trabalhos foto-literários surgiu, redefinindo e expandindo preceitos do naturalismo e realismo francófonos. Em Bruges-La-Morte (1892), Georges Rodenbach (cf. 1998), escritor francófono de origem flamenga, introduziu na literatura ocidental europeia um princípio construtivo de um romance composto por uma relação inédita entre texto e fotografia. Criando um espectro fantasmático sobre a cidade de Bruges, Rodenbach tece, de modo heterodoxo para um naturalista ao recorrer a princípios simbolistas, uma narrativa em que imagem textual e fotográfica tendem à totalidade. Independentemente de seu sucesso, o que Rodenbach faz, indiretamente, é também refletir sobre noções e experiências de presença. Partindo do luto vivido pelo personagem principal, Rodenbach constrói uma narrativa em que a cidade, dotada de sua aura fantasmal, se torna personagem ela mesma. O espaço urbano 
como protagonista de narrativas e reflexões, portanto, encontra respaldo na história belga. Soma-se a isso, a atenção ao fato de, conforme relata Marc G. Blainey (2014), a antropologia ter raramente se dedicado à realidade belga como estudo de caso, ainda que seja esse país um objeto fértil para a reflexão etnográfica, reunindo aspectos políticos, culturais e sociais, que permitem uma rica contribuição à compreensão da sociedade europeia contemporânea, o que também ajudaria a inverter o sinal da antropologia, que até hoje batalha com suas origens coloniais tentando dissipar sua colaboração com a mistificação e centralização de compreensão do mundo a partir de uma perspectiva eminentemente Eurocêntrica.

Finalmente, articulando a questão apresentada, referente às relações de presença no meio urbano através dos vestígios e traços produzidos pelo ser humano, subjaz, no ensaio, relações entre infra e superestrutura explícitas na materialidade que nos rodeia cotidianamente. Trens, edifícios, estátuas e monumentos são produtos do trabalho humano e, nos rodeando, nos põe em relação direta com os frutos do trabalho intelectual e material. Sugerindo tanto o movimento caminhante, pelas passagens e passeios, quanto a monumentalidade da cultura, pelos edifícios e monumentos, estamos sempre em co-presença, como nos testemunha o caminhante solitário que encerra o ensaio. Diante da imensidão do mar, voltamos a nós mesmos como seres sociais por natureza e naturais por sociabilidade (cf. Morin, 1975).

Da presença à co-presença, os vestígios de que tratam esse ensaio podem ser lidos, também, na chave da autoria e da antropologia da fotografia, que compreende a técnica enquanto método problematizando o paradigma da objetividade na ciência social. Se é a fotografia que, aqui, nos permite abordar a questão da presença humana em determinado contexto social, mirando a cultura material, é porque a própria fotografia se dá como vestígio de presença. O autor da fotografia, o operador do aparato fotográfico não faz mais do que transformar a experiência imediata da presença em mediada (cf. Somaini, 2016). A fotografia se torna, assim, meio de percepção através do qual, segundo Walter Benjamin (1996a, 1996b), podemos ler o mundo. Essa leitura é, por si só, um fazer-se presente; é deixar uma marca, um traço, um sinal na e da materialidade humana, bem como um sinal material, seja como fotografia analógica, seja como digital. É, finalmente, a afirmação da impossibilidade de uma ausência completa e definitiva. $\mathrm{O}$ vestígio se torna, assim, aquilo que transforma toda presença em relação de co-presença. 


\section{Referências}

BENJAMIN, Walter. On Perception. In: BULLOCK, Marcus \& JENNINGS, Michael W. (Eds.), Walter Benjamin, Selected Writings Vol. 1, 1913-1926. Cambridge; London: The Belknap Press of Harvard University Press, 1996a, p. 93-96.

BENJAMIN, Walter. Perception is Reading. In: BULLOCK, Marcus \& JENNINGS, Michael W. (Eds.), Walter Benjamin. Selected Writings Vol. 1, 1913-1926. Cambridge; London: The Belknap Press of Harvard University Press, 1996b, p. 92.

BENJAMIN, Walter. Imagens do Pensamento. In: Obras Escolhidas II. Rua de Mão Única. São Paulo: Brasiliense, 2000.

BLAINEY, Marc G. Groundwork for the Anthropology of Belgium: an overlooked microcosm of Europe. Ethnos, p. 1-30, novembro, 2014. Disponível em: <doi:10.1080/00141844.2014.968180>. Acesso em 14 de janeiro de 2017.

MORIN, Edgar. O Enigma do homem: para uma nova antropologia. Tradução: Fernando Castro Ferro, $1^{\mathrm{a}}$. edição, Rio de Janeiro: Zahar, 1975.

RODENBACH, Georges. Bruges-la-Morte. Paris: Flammarion, 1998.

SOMAINI, Antonio. Walter Benjamin's Media Theory: The Medium and the Apparat. In: Grey Room. MIT Press Journals, Vol. 62 (inverno), p. 6-41, 2016. Disponível em: <http://www.mitpressjournals.org/doi/pdf/10.1162/GREY_a_00188>. Acesso em 14 de janeiro de 2017.

Recebido em: 13/10/2017.

Aprovado em: 12/12/2017. 